\title{
Problematizando Práticas Científicas em Aulas de Física: o uso de uma História Interrompida para se Discutir Ciência de Forma Epistemológica-Contextual
}

\section{Problematizing Scientific Practices in Physics Classes: the Use of an Interrupted History to Discuss Science in an Epistemological-Contextual Way}

\section{Hermann Schiffer Brasil \\ Andreia Guerra ${ }^{[1]}$ Brasil}

Em concordância com autores que defendem um estudo sobre as Ciências, encontramos na História Cultural da Ciência um aporte a partir do qual a produção científica pode ser discutida em salas de aula. Entendemos que esse aporte possibilita que práticas científicas sejam identificadas e problematizadas em um estudo sobre as Ciências, na busca de destacar o caráter cultural das mesmas. Como estratégia pedagógica, utilizamos a leitura de Narrativas Históricas pelo potencial do gênero narrativo em envolver estudantes em um tema de estudo, em facilitar a imersão de leitores no contexto histórico estudado e pela maior facilidade de leitura pela linguagem utilizada. Apresentamos uma Narrativa Histórica construída em três partes, possibilitando momentos de interrupção, e propomos sua utilização para problematizar práticas científicas comuns na produção científica da área da Mecânica no início do século XVIII.

Palavras-chave: História Cultural da Ciência; Ensino de Física; Narrativas Históricas.

In agreement with authors who defend a study on Sciences, we find in the Cultural History of Science a contribution from which scientific production can be discussed in classrooms. We understand that this contribution makes it possible for scientific practices to be identified and problematized in a study about the sciences with the purpose to highlight their cultural character. As a pedagogical strategy, we used the reading of Historical Narratives based on the potential of the narrative genre to involve students in studying, to facilitate the immersion of readers in the historical context studied and for the greater ease of reading through the language used. We present a Historical Narrative constructed in three parts, allowing moments of interruption and questioning, and propose its use to problematize common scientific practices in the scientific production in Mechanics in the early eighteenth century.

Keywords: Cultural History of Science; Physics Teaching; Historical Narratives. 


\section{Introdução}

Resultados da pesquisa em educação científica apontam ser a História, Filosofia e Sociologia da Ciência (HFSC) capaz de possibilitar práticas pedagógicas, nas quais não somente um conteúdo é ensinado, mas questões em torno ao processo de construção da ciência são discutidas (Schiffer, \& Guerra, 2015; Martins, 2015; Alvim, \& Zanotello, 2014; Clough, 2009). Considerando ser a HFSC um importante caminho para o ensino das ciências, é fundamental considerar qual linha historiográfica utilizar nos referenciais epistemológicos e metodológicos escolhidos para serem trabalhados em sala de aula. $\mathrm{Na}$ pesquisa aqui discutida, trabalhamos com o aporte historiográfico da História Cultural da Ciência (HCC) (Pimentel, 2007, 2010; Burke, 2008; Videira, 2007; Daston, \& Galison, 2007; Galison, 1987; Klein, 2003). Essa vertente historiográfica reconhece que as ciências são permeadas por valores construídos historicamente (Daston, \& Galison, 2007), de forma que suas práticas são dinâmicas, historicamente contextualizadas, e como tal mudam com o tempo e espaço em que as ciências se desenvolvem (Moura, \& Guerra, 2016; Alvim, \& Zanotello, 2014).

A vertente historiográfica da HCC nasce da crítica a análises estruturais e exclusivamente epistemológica da atividade científica, identificando e estudando as diversas práticas que compõe o empreendimento científico, englobando, assim, práticas não somente laboratoriais. Como exemplos, torna-se objeto de estudo o comportamento de cientistas em grupo, a linguagem utilizada por cientistas (Dodick et al., 2009), as ferramentas teóricas (Klein, 2003), o uso de mecanismos de comunicação e divulgação (Jardim, \& Guerra, 2017; Morus, 2009), as formas de construção de críticas e a legitimação da produção em comunidade (McClellan III, 2003). Deve-se ainda considerar as condições para a construção de espaços de produção de conhecimento científico (Pimentel, 2007), a participação de outros atores normalmente considerados periféricos, como artistas, técnicos e artesãos (Pimentel, 2007) ou a relação entre cientista e instrumento no trabalho empírico (Galison, 1987).

Apesar da escolha da HCC, reconhecemos certos desafios pedagógicos em abordagens históricas para o Ensino de Física. Um ensino de Física pautado em estudos históricos e que pretenda promover discussões sobre as ciências pressupõe uma sala de aula em que o professor não tem o papel de apresentar afirmativas pré-estabelecidas, seja sobre as ciências, seja sobre o conhecimento científico. Entretanto, resultados de pesquisas indicam que a introdução da HFSC no ensino das ciências, e, em particular, no ensino de Física, vai de encontro às expectativas dos estudantes para as aulas das ciências (Henke, \& Höttecke, 2015; Silva, \& Guerra, 2014, Silva ,\& Höttecke, 2010). Essas pesquisas apontam que estudantes e docentes esperam aulas de ciências que apresentem respostas prontas e acabadas sobre fenômenos naturais, e, assim, que não sejam espaços para debates, questionamentos e dúvidas.

Essa não convergência entre expectativas dos estudantes e pressupostos da abordagem histórica faz com que práticas pedagógicas com viés histórico não sejam triviais de serem desenvolvidas na educação básica, levando muitas vezes a dificuldades 
no desenvolvimento de trabalhos e ao abandono de tal perspectiva por parte dos professores (Henke, \& Höttecke, 2015). Essas considerações nos encaminharam à busca por estratégias a serem implementadas em aulas de Física, capazes de promover atividades problematizadoras e dialógicas, com vistas a desestabilizar a resistência dos estudantes à abordagem histórica.

O ler e escrever são práticas que vem sendo incentivadas no ensino de ciências (Gurgel, \& Watanabe, 2017; Hadzigeorgiou, 2016; Almeida et al., 2001). Visando promover um ensino sobre as ciências, o texto pode ser entendido como uma ferramenta para inspirar a reflexão e o debate em sala de aula (Marcuschi, 2010). Essas considerações levaram-nos a considerar resultados de pesquisas que apontam serem a leitura e a escrita estratégias com potencial para trazer o aporte histórico ao ensino, de forma a quebrar resistências dos estudantes a essa abordagem. Para o trabalho com a leitura e a escrita no ensino das ciências, narrativas são apontadas como ferramentas pedagógicas com o potencial de inspirar discussões em aulas de ciências sobre a construção do conhecimento científico de forma reflexiva, contextualizada, motivadora e criativa (Aduriz-Bravo, \& Revel Chion, 2016; Hadzigeorgiou, 2016; Schiffer, \& Guerra, 2012 e 2015; Drummond et al., 2015; Klassen, 2009; Clough, 2011, Klassen, \& Froese Klassen, 2013, 2014; Metz et al., 2007; Norris et al, 2004; Stinner et al., 2003). O gênero literário narrativo recebe atenção na literatura da área de Ensino de Ciências, diante do reconhecimento da sua capacidade de intensificar a relação entre leitor e texto nos níveis emotivo e cognitivo (Aduriz-Bravo, \& Revel Chion, 2016; Schiffer, \& Guerra, 2015; Klassen, 2009a; Bruner, 1990, 2004a). Essa capacidade deve-se, dentre outros fatores, à maior facilidade de interpretação e de criação de empatia desenvolvidas entre leitor e texto que a estrutura e a linguagem utilizadas em narrativas proporcionam (Hadzigeorgiou, 2016; Herman, 2009; Bruner, 2004a). Essa potencialidade das narrativas levou-nos a considerar a hipótese de que tais textos podem potencializar tensões a respeito dos obstáculos à abordagem histórica no ensino de Física.

Frente aos argumentos apresentados, nos últimos quatro anos, nosso grupo de pesquisa desenvolve projetos no ensino de ciências orientados para atividades de ler e escrever narrativas em aulas de ciências e, em particular, em aulas de Física. Uma pesquisa está sendo desenvolvida sobre a aplicação de uma sequência didática com aporte na HCC e inspirada pela leitura e escrita de narrativas de caráter histórico, que chamaremos de Narrativa Histórica $(\mathrm{NH})$. Essa pesquisa encontra-se dividida em duas partes. A primeira, que será apresentada aqui, é composta por um estudo teórico realizado sobre uma $\mathrm{NH}$ construída e que fez parte da sequência didática. Nesse caso, o objetivo foi a construção de uma $\mathrm{NH}$, destacando seus elementos constitutivos e seu potencial de inspirar debates sobre as ciências em sala de aula, pautados na vertente da HCC. A segunda parte da pesquisa, em produção e de caráter empírico, busca analisar que elementos associados às práticas científicas foram elencados pelo professor ao produzir a NH lida em sala e por alunos na escrita de suas NHs, durante um curso de Física de Ensino Médio. 
Como forma de apresentar os resultados da primeira parte da pesquisa, dividimos o presente artigo em três partes. Na primeira, são apresentadas considerações a respeito do aporte historiográfico da HCC, destacando o potencial desse aporte para o ensino da Física. Na segunda seção, discutimos elementos e características de textos de gênero narrativo, destacando como tais características qualificam o uso de narrativas como estratégia pedagógica para o ensino de Física. Na terceira parte e última parte, apresentamos a narrativa construída pelo nosso grupo de pesquisa, elencando, com base no aporte da HCC, o processo de sua construção e os elementos históricos destacados e que podem ser potencializados num trabalho em sala de aula.

\section{A História Cultural da Ciência}

Estudos destacam que houve significativas mudanças na historiografia nos últimos 40 anos (Alvim, \& Zanotello, 2014; McGuire, \& Tuchanska, 2013; Pimentel, 2010; Burke, 2008; Videira, 2007; Pestre, 1996). Dentre essas mudanças, há destaque à expansão que a História da Ciência (HC) sofreu com o aumento de pesquisas, encontros, material e o novo patamar acadêmico alcançado pelos historiadores das ciências (Videira, 2007). Como resultado do crescimento dessa linha de pesquisa, ocorreram mudanças na concepção que historiadores da ciência têm de seu objeto de estudo: a ciência.

Para discutir as mudanças sofridas pela área, Videira (2007) destaca que um dos obstáculos da HC se encontra no eurocentrismo, que torna o estudo do surgimento da ciência moderna na Europa no final do século XVI o "centro de gravidade explicativo da história da ciência" (p. 143). Essa visão apresenta problemas ao destacar que "a ciência teria uma identidade (ou imagem) bem definida e, ainda que não definitiva, suas modificações aconteceriam de acordo com regras racionais e lógicas, fazendo com que essas transformações pudessem ser compreendidas" (p. 143).

$\mathrm{Na}$ contramão dessa visão, surge, no final do século XX, a História Social da Ciência que se consolidou com as "demonstrações" de que o desenvolvimento da ciência não corresponde aos relatos produzidos sobre ele (Videira, 2007). Ao se afastar do viés puramente epistemológico, o estudo sobre a ciência deixou de entendê-las enquanto um corpo ou sistema de proposições ou enunciados que devem ser falsificados por confrontação com a experiência (Pestre, 1996). Nesse movimento, amplia-se o que se considera objeto de estudo da $\mathrm{HC}$, assim como, amplia-se o número de fontes a serem estudadas (Alvim, \& Zanotello, 2014; Videira, 2007).

A linha historiográfica da História Cultural da Ciência surgiu nesse movimento de ampliação do escopo da HC e cresceu através de estudos centrados nas "práticas científicas"1 (Pestre, 1996; Gavroglu, 2007). As práticas científicas aqui não são

\footnotetext{
1 O termo ciência, e, portanto, científico(a) foi cunhado no século XIX, quando da profissionalização dos estudos à época reconhecidos pertencentes à filosofia e história natural. Apesar desse reconhecimento, historiadores da ciência como Juan Pimentel, Lorraine Daston entre outros usam o termo práticas científicas para denominarem as atividades ligadas ao estudo da natureza, mesmo antes do século XIX. Importante destacar o uso da expressão "práticas científicas" não exclui a possibilidade que diferentes atores sociais em diferentes culturas promovam atividades fundamentais para a construção de conhecimento científico (por exemplo, coleta e registro de plantas realizados por nativos na América do Sul).
} 
entendidas somente por práticas laboratoriais ou a prática in loco dos agentes chamados de cientistas, mas são compostas por um conjunto amplo de atividades em diferentes espaços, como o laboratório ou em campo e na divulgação, comunicação e legitimação do conhecimento. Apesar de não únicas e universais, as práticas científicas possuem alguma regularidade e se caracterizam fundamentalmente pelo processo constante de avaliação e crítica das explicações providas pela ciência (Ford, 2015).

De acordo com Moura e Guerra (2016), essas performances são associadas a fatores culturais e socio-institucionais que infundem procedimentos e métodos delegitimação do conhecimento científico em uma comunidade. Assim, não mudam somente as questões, mas também as estratégias e princípios epistemológico-metodológicos defendidos e utilizados por cientistas em suas práticas, como na coleta e seleção de dados, na análise, na crítica, na legitimação e na divulgação do conhecimento construído em busca de respostas (Pimentel, 2010; 2007; Videira, 2007; Daston, \& Galison, 2007; Klein; 2003).

As práticas científicas, entretanto, não estão limitadas a uma série de procedimentos e habilidades universais e infalíveis ou a um método único e objetivo de estudar a natureza. Elas devem ser vistas como práticas construídas, transformadas, compartilhadas e abandonadas em uma comunidade, revelando seu caráter histórico (Daston, \& Galison, 2007). Se os estudos sobre as práticas nos apontam que esses elementos não são universais e atemporais, mas mudam com o tempo e o local, entendemos que o que chamamos de ciência, também é um empreendimento temporal e local (Pimentel, 2007). Em outras palavras, o produto científico é produzido e legitimado em comunidades através de práticas compartilhadas e respondem a questões temporais e locais. Nesse processo, tanto mudam as questões, quanto mudam as práticas aceitas como científicas, sejam experimentais ou linguísticas (Moura, \& Guerra, 2016; Pestre, 1996).

Estudos recentes destacam práticas não comumente consideradas científicas, como fundamentais ao empreendimento científico. Como exemplos, encontramos as atividades de leitura e de escrita no cotidiano de um cientista (Mody, 2015), as escolhas da linguagem a ser usada em materiais compartilhados pelos cientistas e pela divulgação científica (Pimentel, 2007; Dodick et al., 2009; Morus, 2009), as atividades desenvolvidas por atores periféricos, como cirurgiões e parteiras no século XVIII (Pimentel, 2007) ou as próprias atividades relacionadas à "observação" ou "experimentação" (Lundbeck, \& Daston, 2011; Daston 2008). Esses elementos não surgem a priori ou são universais, mas são adquiridos e treinados pelos atores das ciências no âmbito da comunidade científica na qual estão inseridos. Nesse sentido, esses atores também são objeto de investigação da HCC, sendo questionado o papel exclusivo do cientista como sábio que "desvenda" a natureza ao produzir conhecimento (Pestre, 1996).

Importante destacar que além de práticas, entendidas como ações físicas e concretas, encontramos, através da história, diferentes concepções de como o cientista deveria ser e agir. Isso inclui não somente um treinamento em práticas laboratoriais ou de leitura de imagens, mas também um scientific self, que seria descrito e prescrito de forma 
a treinar iniciados nas atividades científicas através de práticas como: o treinamento dos sentidos na observação, o modo de construir diários de laboratório ou o regulamento de crenças e hipóteses pessoais, arquitetando a vontade e concentrando a atenção (Daston, \& Galison, 2007).

Isso nos leva a entender o cientista como um ator social, formado por certo meio a partir da interação com um grupo (Pestre, 1996). Imerso em certa comunidade científica, ele participa de uma cultura, desenvolvendo técnicas experimentais e teóricas compartilhadas nessa comunidade. O treinamento desse "olhar" orienta a sua prática, como na escolha de que experimentos desenvolver ou na definição do que é um "ruído" experimental (Daston, \& Galison, 2007; Galison, 1987). Em cada comunidade, os diversos elementos que compõe a prática científica são discutidos, redefinidos e compartilhados diante da ação dos seus próprios integrantes. Isso nos revela o caráter mútuo de influência entre um indivíduo e seu modelamento em certo meio e a comunidade científica, a partir da constante redefinição desses elementos epistemológico-metodológicos.

Diante de tal entendimento, a HCC aponta para a impossibilidade de definirmos o que é Ciência e como ocorre o comportamento dos seus atores baseado em estruturas rígidas, definidas e universais (Pestre, 1996; McGuire, \& Tuchanska, 2013). Dessa forma, a HCC contribuiu com a Filosofia da Ciência ao favorecer o repensar de significados de termos como 'científico' ou da existência de um único método científico (Thurs, 2015). Mesmo que certas áreas definidas como científicas, como a Astronomia, a Geologia ou a Bioquímica compartilhem algumas práticas ou objetos de estudo, os modos como esses objetos são abordados ou conceitualizados podem ser diferentes (Daston, 2008; Daston, \& Galison, 2007). Essas práticas e olhares mudam não somente com a área, mas também com o tempo (Daston, \& Galison, 2007), o que também questiona a visão de que a ciência segue um mesmo método.

Outra assertiva cara à HCC está em rejeitar o entendimento da ciência como um empreendimento cuja dinâmica se reduza a controvérsias-consensos (Pestre, 1996). Como nos aponta Pestre (1996), todo fechamento de um debate ou consenso é local por natureza (p. 20), o que chamamos de decisão deve ser entendido como o resultado de uma sequência de escolhas intermediárias, "finalizadas" por uma última micro-decisão. O trabalho de Galison (1987) enriquece essa discussão, ao trazer o questionamento sobre quando um experimento "termina", isto é, é aceito como acabado, bem-sucedido. O autor destaca que, na prática laboratorial, o papel de teorias pode ser o de guiar o cientista e possibilitar previsões de resultados, como também o desenvolvimento e manuseio de aparelhos. Porém, tais teorias não são construídas no mundo das ideias sem relação com as práticas desenvolvidas por aqueles cientistas. Na verdade, elas são construídas a partir da interação entre cientistas e as diferentes práticas científicas presentes no contexto analisado.

Galison (1987) destaca que o suposto término de um experimento não está relacionado estritamente com o encontro de uma verdade, mas à análise "bem sucedida" dos dados que estejam de acordo com as questões do contexto analisado. De acordo 
com o autor, quando houver uma teoria bem fundamentada, com previsões precisas, e quando o experimento concordar com o que foi pré-estabelecido, é possível que se encerre o experimento. Isso não significa, necessariamente, que esse resultado será consistente com a posteridade. Por conseguinte, no estudo da prática laboratorial, as motivações para o que buscar, as condições materiais, institucionais e humanas, além das teorias que orientam esse processo devem ser contextualizadas e entendidas como locais e temporais.

Além do laboratório, é preciso considerar outros espaços de produção científica, instrumentos, valores, impactos de teorias, entre outros elementos numa análise micro da produção científica (Videira, 2007). A literatura apresenta trabalhos que contribuem para essa vertente. Como exemplo, temos estudos sobre o impacto de centros de divulgação científica (anfiteatros, zoológicos, jardins botânicos) (Pimentel, 2007), sobre a importância de virtudes epistêmicas para o olhar e o fazer científico a cada época (Daston, \& Galison, 2007) e os que discutem as estruturas metafóricas que permearam o pensamento científico em séculos passados (Pimentel, 2007). Também destacamos os estudos de Burke $(2003,2005)$, que apresentam uma coleção de dados acerca de práticas associadas à construção do conhecimento científico, à constituição de instituições científicas e sobre a detenção do conhecimento.

Buscamos destacar até aqui as novas leituras resultantes da HCC que promoveram um entendimento da ciência como construção complexa, não podendo ser reduzida a um método único e infalível. Através do estudo das práticas científicas, a ciência não se apresenta como produção imparcial, autônoma, autossuficiente e acessível a todos. Ainda assim, as produções científicas promovem mudanças técnicas, tecnológicas e inclusive epistemológicas na sociedade (Carter, 2014; Van Eijck, \& Roth, 2007). Diante disso, o conhecimento científico segue sendo utilizado como justificativa e embasamento em questões políticas, sociais, econômicas e educacionais a nível nacional e internacional.

Por tal motivo, entendemos que uma compreensão da heterogeneidade dos processos de produção do conhecimento científico é importante para o ensino de ciências. E, nesse caminho, defendemos que o estudo das práticas científicas é um caminho para o desenvolvimento de melhores atitudes perante as ciências e para a possibilidade de posicionamento e participação em decisões de caráter sociocientífico (Moura, \& Guerra, 2016; Alvim, \& Zanotello, 2014). Nesse sentido, a escolha do aporte HCC ao ensino de ciências é um caminho para se conciliar o ensino de produtos científicos com estratégias pedagógicas que tragam reflexões sobre as ciências.

Na busca de caminhos para a promoção de atividades pedagógicas que promovam reflexões e debates inspirados no estudo das práticas científicas, consideramos ser importante retirar o estudante da posição passiva e, então, colocá-lo como protagonista do processo educacional. Assim, buscamos ações capazes de levantar questões ao estudante, de forma a suscitar sua manifestação, enquanto o professor se posicione como moderador e promotor de intervenções em sala durante essas ações (Martins, 2015; Metz, 2007). 
Esses pressupostos, aliados aos destaques anteriormente apontados sobre a postura de estudantes em aulas de ciências (Henke, \& Höttecke, 2015), fazem com que práticas pedagógicas com viés histórico não sejam triviais de serem desenvolvidas na educação básica. Então, como responder às expectativas de estudantes e docentes sobre as aulas de ciências apresentarem respostas prontas e acabadas sobre fenômenos naturais? Que atividades pedagógicas, inspiradas pelo aporte na HCC, possibilitam a criação de espaços de debates, questionamentos e dúvidas? Partimos do princípio que uma abordagem histórica, que privilegie um ensino sobre ciências dialógico, pressupõe uma sala de aula em que o professor não tem o exclusivo papel de apresentar afirmativas pré-estabelecidas (produtos científicos). Mais do que isso, entendemos a sala de aula também como um espaço de discussão de conhecimentos não mais considerados verdadeiros, e local de questionamentos de estruturas pré-estabelecidas. Na busca de caminhos, encontramos no uso de NHs potencialidades para contemplar os pressupostos destacados.

\section{Elementos de uma narrativa: uma leitura pedagógica}

O ler e escrever apresentam fundamental importância para o ensino de Ciências na interpretação e construção de significados (Lima, \& Ricardo, 2015; Terra, 2013; Marcuschi, 2010; Machi, \& Leite, 2010; Rivard, \& Straw, 2000). Nessa seção, pretendemos construir argumentos que apontem o texto e o gênero narrativo como caminhos com potencial de possibilitar a realização de atividades pedagógicas com o aporte na HCC no Ensino de Física. O primeiro argumento refere-se à importância de trazermos ao ensino de Física atividades de leitura e de escrita de um gênero e formato textuais diferentes dos comumente utilizados em salas de aula, mas familiares à humanidade (Bruner, 2004b; Herman, 2003, 2009). Visto de uma perspectiva cognitiva, é esperado um maior envolvimento e compreensão pelos estudantes ao se lidar com o gênero narrativo, diante do estímulo ao "pensamento narrativo" (Bruner, 1986).

Não somente na leitura dos textos, mas também na escrita de narrativas encontramos uma atividade, na qual estudantes podem se envolver com as pesquisas em um tema sobre o qual será escrito o texto (Gurgel, Watanabe, 2017; Marcuschi. 2010). Com a ação mediadora do professor na orientação da escrita de uma narrativa, entendemos ser possível que as pesquisas e a escrita realizadas pelos estudantes promovam a reflexão e debates acerca de práticas científicas previamente selecionadas pelo professor ou pelos próprios estudantes no processo.

Em segundo lugar, os atos de ler e de escrever compõem diversas práticas científicas essenciais às ciências. Torná-las objeto de estudo é uma forma de revelar certas práticas não comumente associadas ao fazer ciência. De acordo com Mody (2015), ao se analisar o cotidiano de cientistas em ação, percebemos a importância do ler e escrever na comunidade científica já que grande parte do tempo de um cientista é utilizado na leitura de trabalhos de pares para acompanhar a literatura das suas áreas de atuação. São diversas as manifestações do ler e escrever na produção científica: na 
leitura e escrita de periódicos, livros, ensaios, textos para websites; na construção e escrita de argumentos para defender ideias; ou então o ato de escrever cartas, e-mails, diários de campo, relatórios e resultados de coleta de dados (Burke, 2003). Entender o ler e o escrever como práticas científicas é um caminho para revelar o dinamismo das estratégias utilizadas na busca de validação de um conhecimento frente a uma comunidade científica, destacando, assim, o caráter social da Ciência (Mody, 2015).

Considerando as questões acima destacadas, encontramos na literatura uma atenção crescente para o uso do gênero narrativo no ensino de ciências (Aduriz-Bravo, \& Revel Chion, 2016, Schiffer, \& Guerra, 2015; Murmann, \& Avraamidou, 2014; Froese Klassen, 2013; Klassen, \& Froese Klassen, 2013, 2014b e 2014a; Clough, 2011; Klassen, 2009b, 2009a, 2010; Metz et al. 2007; Metz, 2004 e 2007; Norris et al., 2005). Como forma de identificar o potencial do uso pedagógico de narrativas, uma discussão mais ampla deve ser trazida em relação ao gênero narrativo. Barthes (1977) destaca que encontramos narrativas a todo o momento, em todos os lugares, em todas as sociedades, e que elas surgiram com a própria história da humanidade. Os veículos utilizados para se formar narrativas são diversos: linguagem oral e escrita, imagem estática e dinâmica ou ainda uma mistura de formas. As narrativas são utilizadas por todos os humanos, em todas as classes e, como "a própria vida, está ali, internacional, transhistórica, transcultural" (p. 237). Em outras palavras, a narrativa é uma estratégia básica humana para lidar com o tempo, os processos e as mudanças (Herman, 2009). Não é trivial definir se um discurso, texto ou outra ferramenta semiótica se enquadra no gênero narrativo (Herman, 2009).

De acordo com David Herman (2009), o critério de classificação de um texto não é binário, não bastando a presença de um conjunto único de elementos ou características para se classificar um texto como narrativo ou não. Apesar de não podemos traçar elementos únicos e exclusivos que definam o gênero narrativo, é possível elencar uma série de características que, somadas, são capazes de identificar o gênero de um texto. É possível haver um gradiente da presença dessas características em um texto, de forma que podemos chamar um texto de "mais narrativo" que outro (Herman, 2009). Por tais motivos, apresentaremos brevemente cinco elementos considerados mais fundamentais em uma narrativa: a sequência de eventos, os agentes, o narrador, a estrutura do texto e o "não-falado" (Klassen, 2009a). Esses elementos podem ser chamados de ferramentas literárias (Klassen, 2009a, 2010) e apresentam um potencial pedagógico destacado a seguir.

No grau mais elementar, uma narrativa é um recontar e um modelar eventos, composta por uma sequência temporal desses eventos (Klassen, 2010; Herman, 2009; Norris et al, 2005; Lamarque, 2005; Bruner, 1990). Nessa sequência, há uma mudança de estado com a apresentação de um estado inicial no qual há algum equilíbrio. Esse equilíbrio, entretanto, é quebrado pela ocorrência de algum evento, gerando um estado, onde haverá um novo equilíbrio (Herman, 2009; Klassen, 2010). Essa sequência não precisa ser cronológica e nem toda narrativa necessita apresentar os estágios inicial, intermediário e final. O importante é a existência de mudanças ao longo do texto 
(Herman, 2009). Como os eventos narrados, reais ou imaginários, já ocorreram, é comum que a narrativa seja contada no tempo verbal passado.

Em uma narrativa há agentes, humanos ou humanizados, que são os principais responsáveis pelas mudanças de estado apresentadas no texto ou que sofrem suas consequências (Klassen, 2009a). A possível variedade de tipos de agentes, como origem social, geográfica e financeira, representa uma multiplicidade de consciências, posições ideológicas, políticas e éticas de acordo com cada contexto. Em outras palavras, uma narrativa apresenta a capacidade de fazer com que o leitor vivencie o que é passar por certos eventos dentro de um mundo em fluxo (Herman, 2009). A interpretação da narrativa, também, é, nessa concepção, uma atividade voltada à construção de uma consciência mais diversa e complexa. Essa complexidade é valiosa para o uso pedagógico das narrativas, visto que possibilita que o estudante se depare com visões e contextos diferentes (Terra, 2013).

Muitas das mudanças de estado são geradas por ações dos agentes da narrativa. Nessas ações, constantemente há tomadas de decisões, que envolvem questões éticas, dilemas ou obstáculos a serem superados (Klassen, 2009a; Milne, 1998). Apesar de não serem necessariamente explicitadas no texto, sempre existem motivações, justificativas e impactos das decisões tomadas por um personagem ou por um grupo. Isto é, é possível contextualizar ou, ao menos, promover discussões na leitura de narrativas com esse objetivo, buscando motivações ou correlacionando fatores para entender como certo evento veio a ocorrer. Por isso, é possível que esses elementos sejam destacados de forma a inspirar discussões em sala de aula.

No caso de uma $\mathrm{NH}$ para uso didático, encontramos agentes que participam diretamente ou não da produção científica. Entre esses agentes deve haver uma série de interações cujas motivações ou impactos podem contribuir para a discussão de como o conhecimento científico é construído. Por isso, no processo de construção de uma narrativa com fins didáticos, essa característica deve receber atenção, pois entendemos ser um caminho para o estudo de práticas científicas em sala de aula. Em outras palavras, através de uma leitura do texto orientada pelo professor, é possível destacar e analisar certas ações de agentes da narrativa como constituintes da prática científica daquele recorte histórico.

Em toda narrativa há um narrador, mesmo que oculto (Herman, 2009; Klassen, 2009a). Sobre a relação entre o narrador e o conteúdo de uma narrativa, isto é, entre os eventos que ocorrem e são escolhidos para serem contados, encontramos três possibilidades: o narrador pode ser considerado um agente da narrativa que conta uma sequência de eventos de acordo com sua perspectiva, sem nada saber sobre o que se passa com outros personagens; ou ele pode ser um agente atuante e, assim, participante dos eventos contados; ou, então, ele pode ser alguma consciência externa aos acontecimentos e, assim, ter conhecimento parcial ou total do que passa com os personagens (Taddei, 2009).

Em uma perspectiva meta-textual, três definições eram dominantes há quatro 
décadas, sobre quem é que "nos narra a narrativa" (Barthes, 1977). Primeiro, o narrador emana de uma pessoa (no sentido psicológico do termo) física, o autor. O autor é, então, "o locus de uma permuta constante entre sua personalidade e a "arte" de um indivíduo perfeitamente identificado que, eventualmente, pega uma caneta para escrever uma história" (Barthes, 1977). Logo, a narrativa é apenas uma expressão de um "eu" que existe independente da narrativa.

$\mathrm{Na}$ segunda definição, o narrador é visto como um ser onisciente, impessoal, uma consciência que conta a história de um ponto de vista externo. Mas ele está dentro de seus personagens, pois sabe o que acontece dentro deles e fora, pois não se limita ou se identifica com apenas um personagem. A terceira teoria declara que o narrador deve limitar a história ao que seus personagens sabem ou podem observar, tornando os personagens os transmissores da narrativa.

Barthes (1977) discorda dessas definições no sentido de elas considerarem o narrador e os personagens como figuras reais, pessoas "vivas". O autor defende que narrador e personagens são essencialmente "paper beings" (p. 261), isto é, o autor de uma narrativa não deve ser confundido com o narrador da mesma. O narrador está limitado ao texto e uma leitura semiótica deve ser capaz de detectar seus limites. De acordo com Barthes (1977), "O que fala (na narrativa) não é aquele que escreve (na vida real) e aquele que escreve não é aquele que é” (p. 261). Concordamos com Barthes (1977) que existe uma diferença entre o autor e o narrador, de forma que o narrador é uma manifestação limitada do autor.

Com certa ressonância ao pensamento de Barthes (1977) e de Benjamin (1994, citado por Taddei, 2009) entende que o narrador pode ser visto com dois objetivos, o narrador em instância do processo de comunicação literária e o narrador como catalisador de experiências. No primeiro caso, o narrador é uma entidade que não é um indivíduo real. Ele e o leitor (também visto como uma abstração metodológica) formam um par que constitui um dos elementos da enunciação (Taddei, 2009). Dessa forma, durante toda a narrativa é possível enxergar o enunciado e a enunciação. Por um lado, o enunciado refere-se aos elementos e mudanças ocorridas na história, como o agir dos personagens e a lógica da sequência de eventos. Por outro lado, a enunciação é o processo que enfatiza o ato mesmo de narrar, tendo por sujeitos o narrador e o leitor, sendo que esse processo ocorre de forma diferente para cada leitor e a cada momento diferente.

Como catalisador de experiências, Benjamin considera que o narrador é uma pessoa real ou um personagem que represente uma. Ele seria formado por um personagem capaz de passar experiências úteis de sua vida. Dessa forma, em uma narrativa contada de forma textual, é difícil o narrador de uma história se ocultar frente à sua presença viva nos eventos que compõe o texto (Benjamin, 1994, citado por Taddei, 2009).

Frente aos argumentos apresentados, consideramos que, da perspectiva do leitor, é o narrador quem seleciona quais eventos serão contados, o que será omitido e em qual profundidade (Herman, 2009). Assim, o narrador é entendido como uma manifestação 
do autor (Barthes, 1977), mesmo que oculto, ele apresenta certa visão de mundo. A partir de suas idiossincrasias, o narrador apresenta ideias, opiniões, interpretações, reações a acontecimentos e, em alguns casos, ações, a partir dos quais ele pretende dar forma e sentido à narrativa. Entretanto, esse sentido não é único e nem atemporal, pois o processo de enunciação envolve narrador e leitor. A escrita ocorre em um recorte temporal na qual o autor se manifesta como narrador, enquanto a leitura se inscreve em um presente reiterado, que se aciona a cada vez que um leitor aborda a obra (Milne, 1998).

Dessa forma, do processo de escrita ao processo de leitura existe uma relação que não deve ser entendida como linear entre o autor-narrador-leitor (Barthes, 1977). Não somente existe o fator temporal no processo da leitura (e da escrita), mas esta pode ser feita de forma mediada por uma segunda pessoa, como será o caso da utilização de narrativas em sala de aula.

Além da sequência de eventos, dos agentes e do narrador, existem outros elementos constituintes de uma narrativa que podem intensificar a leitura e a criação de empatia do leitor com o texto. Um exemplo está na estrutura de uma narrativa. Ela deve ser construída de forma a trazer a atenção do leitor e suscitar curiosidade e vontade de querer saber o que acontece em seguida (Klassen, 2009a; Norris et al., 2005). Alguns autores apontam que a atenção do leitor pode ser mantida com a criação de expectativas, instabilidade na vida de agentes e em eventos, suspense e reviravoltas (Hadzigeorgiou et al., 2011; Klassen, 2009a). Dessa forma, a estrutura escolhida para o texto, a forma de organizar e apresentar os elementos como os eventos da narrativa ou o narrador são fundamentais para intensificar as possibilidades da leitura.

Outra ferramenta utilizada na escrita de uma narrativa pode ser chamada de o "não-falado". Na composição de uma narrativa, quaisquer informações que não são explicitadas no texto, mas que apresentam importância na estrutura da narrativa podem ser chamados de o "não-falado" (Klassen, 2009a). Eventos implícitos, significados de termos ou conceitos e resultados de ações de agentes são exemplos que podem ser utilizados em uma narrativa para atrair um leitor. Em uma narrativa, se tudo for apresentado, descrito e explicado é provável que o leitor perca o apetite literário durante sua leitura (Klassen, 2009a). Textos narrativos, em sua maior parte, apresentam uma linguagem característica, apesar de não única (Bruner, 2004a), e são estruturados de forma a desenvolver, no leitor, uma vontade de querer saber mais (Herman, 2009; Gurgel, 2010). Seja o destino de um agente ou a resposta de um enigma, há certa necessidade de não se apresentar todas as informações para o leitor, deixando seu apetite literário não completamente saciado (Klassen, 2009a).

Stephen Klassen (2009a) aponta que quando um texto se completa e tudo é dito o mesmo pode se tornar pedante para o leitor. Tal frustração é resultado do envolvimento a nível emotivo que existe durante a leitura de uma narrativa que inclui o questionamento, a reflexão e a busca de respostas durante o texto (Herman, 2009). No caso de NHs para o uso didático, abre-se a possibilidade de que o "não-falado" esteja relacionado 
ao conteúdo histórico e científico. Como exemplo, podemos sugerir a não explicação de algum conceito científico apresentado durante o texto importante para os agentes da narrativa. Outro exemplo poderia ser o destaque a eventos que foram resultados das ações de algum personagem, mas sem que essas ações sejam previamente descritas, inspirando ao leitor a questão "Por que isso ocorreu?" ou "Quem foi o responsável por isso?".

É importante reiterar que o "não-falado" pode ser visto como uma característica de qualquer texto, pois nunca um texto apresenta todas as informações para seu leitor de forma exaustiva. Tornar o não falado característica inerente a qualquer texto é generalizar erroneamente o não falado, pois em uma narrativa esse se refere a quando o autor deixa propositalmente de fornecer uma informação com o propósito de instigar a curiosidade do leitor. Por tal razão, consideramos ser de vital importância o professor que utilize NHs em sala de aula seja um mediador do texto, levantando questões dos estudantes e promovendo debates com a turma.

Como a efetivação de debates requer a atenção e participação dos estudantes, é importante o uso das estratégias literárias em pontos-chaves na narrativa com o objetivo de suscitar a vontade de querer saber mais dos estudantes. Em conjunto com a mediação do professor, espera-se que as discussões levantadas suscitem a curiosidade dos estudantes e os tragam a uma posição de protagonistas nessas discussões.

Por último, destacamos que em uma NH, a seleção do conteúdo e a estrutura do texto devem seguir uma fidelidade historiográfica, evitando leituras mal fundamentadas ou exageradas (Forato, 2012). Além disso, no contexto do ensino de ciências, é importante não apresentar valores (Milne, 1998) incoerentes com pesquisas em História Cultural da Ciência. Ainda assim, apesar de parecer uma tarefa excessiva em critérios e armadilhas para um educador em ciências, que não é escritor e nem historiador, acreditamos que existe uma liberdade criativa na escrita de narrativas importante para a sala de aula (Hadzigeorgiou et al., 2011; Klassen, 2009a, Schiffer, \& Guerra, 2015).

\section{Potencial Pedagógico de Narrativas Históricas}

Até aqui foram apresentados alguns dos principais elementos que compõem um texto narrativo. Adiante, são apresentados resultados de pesquisas que discutem as NHs enquanto caminho pedagógico. Defendemos como Aduriz-Bravo e Revel Chion (2016); Clough (2011) e Klassen (2009a) que a NH deve estar estruturada buscando intensificar a empatia criada entre o leitor e seus agentes, com vistas a intensificar a compreensão do contexto e das condições nas quais certas ações foram tomadas. Como resultado, a atenção e curiosidade durante a leitura devem facilitar a interpretação, pelo leitor, de sentidos e valores presentes no texto, e possibilitar que este se sinta "imerso" no cenário, temporalmente e geograficamente (Herman, 2003).

Ao se utilizar NH no Ensino de Ciências, um dos resultados esperados da interação entre leitor e narrativa é que o conteúdo estudado torne-se mais memorável (Hadzigeorgiou, 2016; Klassen, \& Froese-Klassen, 2014a; Klassen, 2006). Bruner (1990) 
defende que nós organizamos nossas experiências e memórias de acontecimentos na forma de narrativas, em histórias, mitos e razões para se fazer ou não algo. Encontramos pesquisas que corroboram essa proposta, indicando que o formato narrativo estimula a imaginação e provoca reações no nível emocional através das quais estudantes assimilam mais com a memória a longo prazo do que com a realização de exercícios (Klassen, \& Froese-Klassen, 2014a; Klassen, 2006; Graesser, 1981; Graesser et al., 1980) e que estudantes se dedicam mais ao ato de ler, quando leem narrativas, em contraste com a leitura de textos expositivos (Zabrucky, \& Moore, 1999).

Entretanto, apesar de haver um sentido proposto pelo(s) autor(es) em uma narrativa, reconhecemos que a interpretação de um texto em sala de aula é um fenômeno pedagógico e social, com reflexos em eventos e ações dos agentes do texto (Terra, 2013; Milne, 1998). Um mesmo texto não é lido duas vezes da mesma forma, pois as condições nas quais ele é lido nunca são iguais (Taddei, 2009). Mesmo que seja lido repetidamente, em sequência, o leitor não é o mesmo de antes da leitura.

Outro fator importante a ser considerado é que a leitura da $\mathrm{NH}$ sem orientação parece não potencializar o poder pedagógico da mesma (Metz, 2007; Metz et al., 2007). Pesquisas apontam que a partir da leitura não orientada de textos científicos (histórias ou reportagens) estudantes se manifestaram a favor da autoridade científica, apresentando certezas em suas afirmações, apesar de os textos apresentarem argumentos contrários (Philips, \& Norris, 1999). Philips (2002), por exemplo, aponta que a habilidade inferencial de estudantes foi identificada como fraca após a leitura de textos. No trabalho do autor, os estudantes se prenderam à pura localização de informações no texto e não produziram interpretações esperadas na seleção do mesmo. Assim, o autor sugere ser necessária maior competência literária e instrução para interpretações mais complexas. Em Brill e colaboradores (2004), resultados apontam que estudantes tiveram dificuldades com a linguagem científica e com o estilo do texto, de forma que reagiram às mesmas, associando as questões destacadas no texto com conhecimentos prévios, desprezando os termos técnicos e insistindo em realizar perguntas sobre o texto ao professor.

Ainda que haja um sentido proposto numa narrativa, certas informações ou eventos não são contados e nem todos recebem a mesma importância. Logo, na construção de uma narrativa, há influência e presença de valores humanos e culturais (Milne, 1996b, 1996a, 1998). A seleção de eventos e a forma como eles são apresentados pelo narrador são centrais no uso de narrativas com viés pedagógico. Isto porque essa seleção acaba por direcionar certas interpretações desses eventos, destacando valores e contribuindo na construção de ligações emocionais (Milne, 1998). Concordamos com Metz e colaboradores (2007) que existe uma tensão na criação de NHs entre um texto narrativo que vise descrever todos os detalhes no desenvolvimento histórico e um que busque promover discussões sobre as ciências, sem resultar em meras descrições de questões de História da Ciência.

Durante a construção de uma $\mathrm{NH}$, certos sentidos relacionados ao processo de produção científica são atribuídos pela seleção de eventos ou estrutura do texto. Entretanto, esses sentidos podem não ser interpretados durante a leitura. Considerando 
que reflexões ocorrem no nível individual durante a leitura, mas que podem ser orientadas e potencializadas pela mediação realizada pelo professor (Terra, 2013), entendemos ser fundamental a mediação do professor para destacar os sentidos do texto, que, na leitura, não foram interpretados pelos estudantes. Assim, ao usar uma NH, é importante que o professor elenque objetivos no início do processo, mesmo que estes mudem durante as atividades pedagógicas.

Outra característica do uso de narrativas é o tipo de linguagem utilizado. Estudos apontam ser a linguagem presente nesse tipo textual mais familiar ao estudante (Herman, 2009; Holiday et al., 1994) e menos carregada de elementos verbais, matemáticos e imagéticos como os textos dispostos nos livros didáticos (Martins, 2012, p.21).

A partir das questões levantadas, no último tópico, apresentamos uma $\mathrm{NH}$ construída por nosso grupo de pesquisa, que teve por objetivo levantar discussões a respeito das ciências, com foco nas práticas científicas.

\section{Práticas Científicas na Narrativa Histórica}

As ferramentas literárias utilizadas na construção da narrativa a ser apresentada foram inspiradas nos trabalhos de Schiffer e Guerra (2015), Klassen (2009a, 2010) e Metz (2007). A partir de Metz (2007), construímos a narrativa dividida em três partes, de forma a possibilitar intervenções durante a leitura do texto, como o levantamento de questões sobre as temáticas e o conteúdo histórico e científico apresentados. Apesar de as partes do texto serem ordenadas cronologicamente, cada uma apresenta cenários, personagens e eventos diferentes.

A narrativa aqui discutida faz parte de uma pesquisa maior desenvolvida em aulas de Física, cujo tema estudado era Mecânica. Essa particularidade levou-nos a recortar como tema as diferentes posições de Gottfried W. Leibniz (1646-1716) e Isaac Newton (1643-1727) frente a conceitos de espaço e tempo, à necessidade de conservação de movimento no Universo, além da disputa da originalidade no desenvolvimento do Cálculo Diferencial. Dessa forma, escolhemos para compor a narrativa o intervalo de tempo de 1666 a 1716 (50 anos), abrangendo o período que vai do início da juventude de Leibniz até seu falecimento. Foram escolhidos como principais agentes do texto: Leibniz, Newton e Christian Huygens (1629-1695), entre outros filósofos naturais com os quais Leibniz desenvolveu debates e disputas, como Samuel Clarke (1675-1729) e Fatio de Duillier (1664-1753) (Kreiling, 1968; Hofmann, 2007; Fitas, 1993; Newton, 1979; Leibniz, 1974, 1976; Iltis, 1973).

Diante de nossos objetivos pedagógicos e pressupostos teórico-metodológicos, o aporte historiográfico da HCC orientou a construção da narrativa. Assim, na construção da $\mathrm{NH}$ consideramos importante destacar elementos associados às práticas científicas do episódio histórico. O primeiro elemento ressaltado foi a troca de cartas, uma prática científica fundamental para o desenvolvimento da ciência naquele contexto, representada pelo que tem sido chamado na literatura de República das Letras (Brockliss, 2013). O segundo foi o espaço de difusão e produção de conhecimento das academias científicas 
locais. Por último, a disputa pela primazia do Cálculo Diferencial, ilustrando processos de disputa e legitimação do conhecimento.

A República das Letras, uma comunidade virtual, era formada por cidadãos que utilizavam a troca de correspondências escritas como caminho para divulgar seus trabalhos científicos (Brockliss, 2013; Burke, 2011; Daston, 1991). Entre filósofos naturais, este se tornou o principal meio de comunicação e, de certa forma, a chave para a subsistência no campo científico (Jardim, \& Guerra, 2017; Brockliss, 2013). Os filósofos naturais que estavam mais conectados na rede de troca de correspondências eram os que mais estavam atualizados e os que mais tinham seus trabalhos difundidos. Assim, os mais influentes mantinham um número de ouvintes atentos e interessados em contribuírem com a comunidade e crescerem na hierarquia da República. A maioria das instituições de ensino possuía ao menos um integrante da República das Letras (Brockliss, 2013).

O número de integrantes da República cresceu diante da ampliação dos serviços postais estatais no final do século XVII (Brockliss, 2013), chegando a 30.000 membros em fins do século XVIII. Esses membros estavam principalmente na Europa, mas também em colônias europeias. A presença de mulheres na República não era forte (Pal, 2012) e, mesmo havendo a contribuição de centenas de participantes periféricos (Brockliss, 2013; Pal, 2012), a comunidade permaneceu restrita a, praticamente, homens brancos de classes alta e média (Burke, 2011).

Entrar na comunidade não era tão complicado, bastando saber latim e ter interesse por alguma área das ciências ou humanidades, além de ter conhecimento de livros que estivessem dentre os considerados relevantes à sua área de interesse (Jardim, \& Guerra, 2017). A República, teoricamente, era guiada pelo ideal de estar a serviço da moralidade e da melhora da humanidade, de forma que seus participantes não deveriam pautar-se em interesses próprios (Brockliss, 2013; Jardim, \& Guerra, 2017). Entretanto, na prática, a realidade era outra. Muitos dos participantes buscavam interesses pessoais na comunidade e alguns se aproveitavam de sua posição hierárquica (Brockliss, 2013; Daston, 1991). Crescer na hierarquia da República nem sempre era resultado dos trabalhos realizados. A rede de influências, que poderia ser originada de uma condição financeira ou política, era também muito importante para a posição hierárquica na comunidade (Brockliss, 2013).

Apesar dos poucos pré-requisitos para "entrar" na República das Letras, a disputa por ter seu trabalho reconhecido era intensa entre filósofos naturais, médicos, advogados, membros do clero e membros da nobreza que se aventuravam no estudo da natureza (Brockliss, 2013). Ter algum dos líderes da República como patrono era um grande desafio. Para ascender na República das Letras, era necessária alguma mercadoria de troca, como "livros, sementes, moedas, artefatos ou instrumentos" (Brockliss, 2013). Consequentemente, a rejeição de cartas por certas figuras mais influentes poderia ser fatal para a posição de um cidadão na República (Jardim, \& Guerra, 2017).

Ainda assim, apesar das vantagens de ter um patrono, esse não era o único 
caminho para se tornar reconhecido na República das Letras. Era possível buscar aprovação através de academias e sociedades científicas (Jardim, \& Guerra, 2017). No recorte histórico escolhido, as duas principais academias científicas europeias, a Royal Society de Londres (1660) e Academia de Ciências de Paris (1666), foram um marco na institucionalização das ciências (McClellan III, 2003; Daele, 1977). Ambas contavam com o auxílio e patrocínio reais e receberam privilégios como o poder e autoridade da impressão de seus trabalhos ou o uso de cadáveres de pessoas executadas para realização de dissecações (Daele, 1977). Ambas as academias se tornaram "centros de excelência", compostas por um grande número de filósofos naturais renomados. Dentre as atividades desenvolvidas nelas, havia a repetição de experimentos realizados por filósofos naturais que não necessariamente integravam essas academias, além da análise de escritos de diferentes filósofos naturais (McClellan, 2003; Daele, 1977). Assim, podemos dizer que, no século XVIII, as academias científicas seriam uma forma institucional da "República das Letras" (Goodman, 1996).

Newton foi presidente da Royal Society por 24 anos (1703-1727), período no qual houve a disputa pelo Cálculo Diferencial. Apesar de ser conhecido por não se corresponder com muitas pessoas e não se manifestar publicamente sobre assuntos profissionais ou pessoais, os trabalhos de Newton foram defendidos por outros integrantes da Royal Society, como Fatio de Duillier e Samuel Clarke. O primeiro foi protagonista na acusação de plágio dos trabalhos de Leibniz. Em 1699, Fatio de Duillier escreveu um livro de Geometria, no qual atribuía sem questionamentos a originalidade do Cálculo Diferencial a Newton, enquanto questionava a reivindicação de Leibniz sobre a mesma. Por outro lado, Samuel Clarke foi responsável por uma série de trocas de cartas para a princesa de Gales, Carolina de Ansbach (Pal, 2012), nas quais conceitos newtonianos como espaço e tempo foram debatidos. Enquanto Samuel enviava cartas à princesa, Leibniz também o fazia, formando assim um debate que durou quase dois anos, até a morte de Leibniz em 1716 (Fitas, 1993).

A partir do reconhecimento da importância desses elementos nas práticas em torno à temática selecionada, a narrativa foi construída. Os agentes escolhidos para a narrativa são personagens históricos centrais que servem como bons exemplos para os três aspectos da prática científica. Há espaço para o estudo biográfico de cada um deles, mas na narrativa há uma ênfase a aspectos da vida profissional de Leibniz. Leibniz era uma figura influente na República das Letras (Ross, 2015; Marras, 2011; Jolley, 1994) e se envolvia tanto com assuntos das ciências, quanto das humanidades, haja vista sua vasta produção.

\section{A Construção da Narrativa Histórica}

A NH foi escrita em três partes, inspirada em Metz (2007), para possibilitar interrupções que favoreçam ao professor discutir o texto e levantar questões. $\mathrm{Na}$ sequência, são apresentadas as três partes que compõem a NH e destacamos os objetivos de cada uma, enfatizando as ferramentas literárias utilizadas e as práticas científicas 
passíveis de serem trazidas para discussão em sala de aula.

A primeira parte do texto foi intitulada Um almoço nobre e foi construída de forma a ser uma leitura introdutória, familiarizando o estudante com o gênero literário e com a temática escolhida para a NH, além de apresentar informações biográficas de Leibniz.

Para a primeira parte, criamos um narrador onisciente e que não participa dos eventos. Assim, ele apresenta informações sobre o cenário, sobre as ações e pensamentos do personagem Leibniz. Apesar de não apresentarmos as opiniões do narrador, ele realiza uma leitura interna do personagem de Leibniz, como se fosse a sua consciência falando ao leitor. Dessa forma, esperamos que os estudantes se identifiquem com o personagem e criem uma empatia com ele, diante de sua situação enquanto jovem, com suas emoções, desejos e objetivos pessoais.

Em relação aos eventos escolhidos, Leibniz é apresentado como um jovem, que há poucos meses defendeu sua tese de doutorado. Demos destaque à sua motivação de ingressar na vida acadêmica e do Direito e outras informações biográficas, como a rejeição de sua tese na Universidade de Leipzig. Inspirados pelos escritos de Leibniz em filosofia (Leibniz, 1974), atribuímos pensamentos a Leibniz relacionados ao Princípio da Razão Suficiente, que ele desenvolveu durante sua vida (Jolley, 1994). Nossa motivação foi trazer pequenas referências à sua produção literária e um suposto conjunto de questões que motivaram seus escritos filosóficos.

Enquanto ocorrem os eventos no tempo presente do texto, o narrador traz ao leitor informações sobre o passado de Leibniz, como a morte de seu pai e seu amor à leitura. Destacamos o gosto de Leibniz pela leitura com o objetivo de demonstrar como os atos de ler e de escrever são práticas importantes não somente para a vida política, mas também para a vida acadêmica do filósofo.

\section{Parte 1 - Um almoço nobre}

"Por que as coisas existem? Por que são como são, e não de outro modo?" Era cedo, e essas palavras preenchiam a mente de um jovem enquanto procurava uma roupa elegante o suficiente para almoçar com um Barão. Papéis rabiscados tomavam sua mesa e parte do chão, enquanto o estalar de sua lareira tentava distrai-lo inutilmente. Nada iria impedi-lo de impressionar o recém-conhecido nesta ocasião. Esta era uma chance de se afastar da vida acadêmica e ingressar no mundo das leis, do Direito, e realmente beneficiar a humanidade.

Talvez tenha sido este seu pensamento logo após a defesa de sua tese, De Casibus Perplexis, que lhe conferiu o título de Doutor em Direito em fevereiro daquele mesmo ano, 1667. A reação da plateia lhe deixou entusiasmado e ali ele soube que havia tomado a decisão certa ao mudar para a Universidade de Altdorf. Fora uma difícil decisão abandonar a Universidade de Leipzig, mas seu título de Doutor havia sido rejeitado por uma razão pífia: ele ser "jovem demais". "Para tudo encontramos uma razão, mesmo que discordemos dela” - pensou ao abotoar sua melhor camisa.

Figura1. Parte 1 - Um almoço nobre (continua) 
Talvez seja prudente eu levar uma cópia de minha dissertação; o barão Johann von Boyneburg pode se interessar em lê-la após a refeição! A ideia de carregar páginas de textos e ler antes ou após a refeição não lhe soava estranha, pois desde cedo seu amor pela leitura fora bem reconhecido. Talvez por sorte, após a morte de seu pai, ganhou acesso à sua biblioteca particular. Desde então, não parava de ler todos os livros, cartas e rascunhos nos quais conseguia colocar as mãos.

Recomponha-se, imediatamente. Dessa forma, suprimiu sua ansiedade e, elegantemente, saiu à rua com um passo firme enquanto o vento gélido da cidade de Mainz lhe cortava o rosto. Sua ansiedade também era devida à possibilidade de o Barão ter convidado um político influente da cidade, o Arcebispo J. P. von Schönborn. Certamente sua vasta leitura, tanto sobre direito, quanto teologia, o auxiliaria nas discussões que tomariam a maior parte do almoço. Através do arcebispo, sua esperança seria a possibilidade de participar de uma tão necessária reforma jurídica do Sacro Império RomanoGermânico. E, mesmo com toda sua instrução, etiqueta e disciplina, o jovem Gottfried Wilhelm Leibniz notou que suas pernas tremiam. E não era somente pelo frio.

Figura1. Parte 1 - Um almoço nobre (continuação)

Nos parágrafos finais, os nomes do barão e do Arcebispo com os quais Leibniz pretende almoçar são apresentados. A partir da introdução desses dois personagens, que foram patronos marcantes para a vida política de Leibniz (Jolley, 1994), buscamos destacar a importância da construção de uma rede de contatos influentes para a vida política e acadêmica do filósofo. Ao final do texto, buscamos contextualizar geograficamente o cenário da NH na cidade de Mainz, no Império Romano-Germânico, e trazer informações sobre um futuro projeto jurídico para o Império, do qual Leibniz participou.

A construção das partes 2 e 3 da NH, com destaque à segunda, foi inspirada em cartas que Leibniz trocou com Christian Huygens, Samuel Clarke (Kreiling, 1968; Hofmann, 2007; Fitas, 1993; Iltis, 1973) e com a princesa de Gales, Carolina de Ansbach (Pal, 2012). A segunda parte foi intitulada A carta incompleta.

\section{Parte 2 - A carta incompleta}

Parecia que seu sonho havia se realizado. Com o apoio do duque Ernst Augustus, Leibniz teve acesso a arquivos e bibliotecas que tanto almejava para a construção de um grande trabalho. Produzir uma genealogia da família Brunswick não seria fácil, mas daria direitos, como o de reivindicação de terras, aos seus membros. Além disso, traria financiamento para Leibniz continuar suas viagens pela Europa.

Já havia passado mais de dez anos após a morte de Boyneburg, em 1672, e de Schönborn, em 1673, influências que tanto lhe alavancaram na vida política. Diante das missões diplomáticas e políticas para as quais fora incumbido, Leibniz conseguiu viajar para cidades como Londres, Delft e Paris. Sua vida política havia sido agitada. Em certo momento, negociou a paz entre Inglaterra e Países Baixos, enquanto em outro incentivou a invasão francesa no Egito. Assim, livraria os Estados Germânicos do perigo ao lado.

Figura 2. Parte 2 - A carta incompleta (continua) 
Durante estas viagens, Leibniz se encantou com a vida científica e intelectual, principalmente de Paris. Esteve em contato e pôde travar debates científicos com filósofos naturais como Hooke, Boyle, Oldenburg, Leeuwenhoek e Christiaan Huygens.

A troca de cartas com alguns deles lhe rendeu intensas reflexões sobre a natureza. Mal Leibniz havia sentado para terminar uma delas, um assistente lhe trazia novos documentos oficiais da cidade de Hanôver que o tomariam sua atenção durante horas. Enquanto isso, a carta lhe esperava...

"Caro Sr. Huygens, tanto gostaria de ouvir sua opinião enquanto termino meu ensaio sobre o que acredito ser a real medida do movimento. Entretanto, sinto que posso distraí-lo da montagem de sua obra. Minha crítica ao trabalho do Sr. Descartes deve vir a refletir sobre a sua concepção do movimento, além de poder ser reconhecida de modo negativo perante membros da Académie des Sciences. Se minha afiliação já fora rejeitada, é possível que nunca venha a ser concretizada, caso este temor se torne real.

Não me parece que a tal grandeza, definida pelo tal e compartilhada pelo senhor, como quantidade de movimento sirva como medida verdadeira do movimento. Da maneira como ela tem sido proposta, dois corpos que contenham medidas iguais, mas com sentidos opostos, apresentariam um total desta grandeza de valor nulo. Seria difícil fazer-me crer que Deus teria criado o movimento e atribuído aos corpos uma "força motora", cujo valor total seja nulo; mesmo que se conserve, como ambos vem demonstrado. Venho tentado demonstrar que podemos reconhecer outra grandeza, responsável pela dinâmica universal, que se conserva em todos os corpos, uma verdadeira força viva à qual nomeei "vis viva". Esta, uma grandeza que não depende do produto da massa pela velocidade de um objeto, mas pelo quadrado da velocidade.

Concordemos que o movimento é relativo, apesar de suas colocações acerca do movimento circular. Mesmo diante da dificuldade de identificarmos o movimento constante, caso não contemos com nenhum referencial confiável, não podemos associá-lo somente a uma mudança de posição: a causa do movimento deve ser uma força inerente a cada corpo. Eis que proponho que nos debrucemos sobre a vis viva. Como o senhor mesmo poderá deduzir, esta grandeza é conservada nos casos de colisões elásticas trabalhados por ti e pelo Sr. Descartes. Temo que ambos, e outros, a rejeitem diante da dificuldade de enxergar sua conservação em colisões inelásticas, mas lhe digo: ela pode parecer se desfazer aos nossos olhos, mas perdura em cada parte dos corpos em questão.

Com efeito, Deus a teria criado como uma realidade física última, conservada durante nossa existência, compondo um universo eterno, o melhor arranjo que um mundo possa apresentar. A nós nos cabe sua medida, a qual podemos encontrar, inclusive, na altura que um corpo é capaz de subir e que é facilmente determinada pelas deduções de Galileu e relacionada à $\mathrm{mV}^{2}$.

Apesar de concordarmos com o princípio da conservação, creio a real medida do movimento a vis viva e não a proposta em vossos trabalhos. Tomarei um tempo para organizar meu material e lhe enviarei uma versão assim que possível. Além disso, tenho considerações sobre sua teoria dos vórtices...."

Diante de tantos papéis ofuscando a carta, seus escritos somados a documentos oficiais, se Leibniz iria se lembrar de termina-la e enviá-la, não sabia a resposta.

Figura1. Parte 1 - Um almoço nobre (continuação) 
Apesar de se passar anos depois do contexto da $1^{\text {a }}$ parte da $\mathrm{NH}$, o início da segunda parte foi escrito de forma a ser uma continuidade da primeira, com a conclusão de alguns dos eventos pressagiados nesta. Nessa parte, são dadas mais informações sobre a vida política de Leibniz e o impacto que seus mentores, já falecidos nesse momento, tiveram nela, além de sua tese da vis viva e questionamentos sobre o conceito de quantidade de movimento de Huygens. Destacamos como sua vida política lhe possibilitou constantes viagens pela Europa, a partir das quais ele veio a conhecer e se interessar pela produção científica da época. Com essas viagens, ele conheceu filósofos naturais e buscou a aceitação de membros da Royal Society e da Academia de Ciências de Paris, iniciando assim sua troca de cartas com Huygens (Kreiling, 1968). Dessa forma, inseriu-se nos círculos de filósofos naturais da Inglaterra e da França, tornando-se um cidadão da República das Letras (Marras, 2011).

No início do texto, o narrador tem o mesmo formato da primeira parte: ele é onisciente e não participa dos eventos. Entretanto, na segunda parte, o narrador não tem a mesma importância como ferramenta literária, pois tal parte da narrativa é centrada em uma suposta carta que Leibniz escreveu a Huygens. Baseada na literatura (Kreiling, 1968; Hofmann, 2007; Fitas, 1993; Leibniz, 1974, 1976), o conteúdo da carta foi criado por nosso grupo de pesquisa. Isso nos possibilitou apresentar uma das formas como filósofos naturais do século XVII defendiam teses, criticavam outros autores e, ao mesmo tempo, tinham seus trabalhos divulgados: através das cartas (Jardim, \& Guerra, 2017).

Deve-se ainda destacar que a opção pela carta como elemento condutor da NH nos permitiu estruturar o texto num formato que se assemelha a um diálogo, em que apenas um dos lados é ouvido (Herman, 2009). Assim, utilizamos a carta também como um recurso literário para dispor não-ditos no texto. Isto por que como ela é endereçada a alguém (Huygens) envolvendo um debate que já ocorria há certo tempo, nem tudo precisaria ser explicado. Por exemplo, a primeira frase do terceiro parágrafo é um trecho que destaca uma grandeza não referenciada ao leitor anteriormente. Porém, por ser uma carta à Huygens, a crítica pode ser destacada sem que a grandeza seja explicada. Entendemos que aqui há um potencial de não somente suscitar a curiosidade dos estudantes sobre o conteúdo da carta, mas também discutir o cotidiano de um filósofo natural da época, envolvido em debates contínuos com argumentações de caráter filosófico, matemático e religioso.

$\mathrm{Na} \mathrm{NH}$, Leibniz defende a vis viva, enquanto critica o conceito criado por Descartes e estudado por Huygens: a quantidade de movimento. O próprio Leibniz reconhece, a partir da carta, que há críticas à vis viva pelo fato de a mesma não parecer se conservar em colisões inelásticas, porém responde às críticas afirmando que a mesma fica "em cada parte dos corpos em questão”. No sétimo parágrafo, Leibniz apresenta razões teológicas para haver uma grandeza relacionada a movimento que se conserve em todo o universo, questão essa discutida no Princípio da Razão Suficiente. Novamente, encontramos trechos com "não-ditos", como no final da carta, com a menção aos estudos de Huygens 
e à teoria dos vórtices de Descartes. Essa parte da NH se encerra levantando a hipótese de que essa carta não seja terminada e enviada, possibilitando que o professor destaque que essa carta foi inventada pelos autores da NH.

A terceira e última parte da NH é intitulada Uma controvérsia matemática foi construída com o propósito de gerar discussões acerca da disputa da primazia do Cálculo Diferencial entre Leibniz e Newton:

\section{Parte 3 - Uma controvérsia matemática}

Se eu reconheço o nome "Newton"? Sim, está surpreso? Já o ouvi antes de você, aposto, mas isso faz tempo. Lembro-me bem daquela época. As ruas imundas e os mercados lotados, em uma mistura de odores, onde era possível captar alguns dos maravilhosos perfumes da alta cultura cruzando ao som das carruagens. Mas, o que mais se sentia nas ruas era o cheiro de estrume, mesmo.

Mesmo após tornar-se eleitorado, a cidade de Hanôver não conseguiu esconder o contraste entre seus habitantes. Naquele tempo, eu morava lá e percorrer longas distâncias pelas suas ruas era minha especialidade; cruzando ruelas, utilizando atalhos e atravessando a multidão nas praças me tornava um garoto de entregas excepcional. Em certas entregas, eu conhecia gente importante, daquele tipo que interrompia o odor das ruas. Houve um senhor a quem o nome "Newton" não agradava nem um pouco, a quem nunca irei esquecer.

Era início de 1699 e eu me dirigia para entregar uma carta ao Sr. Gottfried W. Leibniz, o mesmo que ajudou àquela cidade a torna-la eleitorado. Sua casa era imensa, eu até perdi a conta do número de andares. Ao invés de ser recebido por serviçais, fui atendido pelo próprio, que me recebeu com toda cortesia que alguém visivelmente ansioso conseguiu dispor. Não era apropriado, mas, diante do frio, eu aceitei entrar para tomar uma bebida quente; eu mereço!

Ao abrir e ler a carta, o Sr. Leibniz não pode conter a irritação. "Como pôde este recémingressado me contestar? Absurdo!" - soltou, mal notando que eu estava a observar. Perguntei-lhe se estava bem e, ambos encabulados, ingressamos em uma conversa bastante complicada para minha pessoa, mas que me entreteve e me mostrou um jeito de pensar que nem imaginava.

Ao que me lembro, pouco tempo antes, um tal de Fatio de Duillier havia escrito um tratado no qual o acusava de ter roubado as ideias sobre uns novos métodos matemáticos de um outro senhor, chamado Newton. Aparentemente, na carta estavam tentando tranquilizá-lo, pois ninguém aceitaria as acusações de um membro mais novo que ele (e suíço!) de uma sociedade chamada Royal Society, que ficava em Londres. Ainda assim, este trabalho havia sido publicado e estava sendo bastante discutido nos corredores daquela sociedade por defensores dos princípios matemáticos de Newton, inflando as críticas sobre sua originalidade matemática.

"Meus métodos são inovadores, absolutamente originais! Veja só, meu caro, enquanto o Sr. Newton propõe um método no qual as variações das funções são comparadas ao movimento de corpos, em meus trabalhos eu exploro questões mais fundamentais. Acredito que este próprio Duillier não tenha a capacidade de compreender questões profundas sobre geometria, quanto menos o significado de trabalhar com quantidades infinitamente pequenas, como eu proponho!"

"Desculpe-me, senhor, mas eu não compreendo o que está me explicando. Como assim, quantidades infinitamente pequenas?"

Figura 3. Parte 3 - Uma controvérsia matemática (continua) 
"Perdoe minha catarse. Duvido que minhas inquietações sejam do seu interesse. Mas, diante da sua pergunta, lhe retorno outra: que natureza seria a nossa se pudéssemos dividir certo corpo até encontrar um pedaço fundamental, um limite, um final? Não seria isto um absurdo? Um universo limitado, finito, composto de pedaços fundamentais iguais é o desejo daqueles que creem alcançar a onisciência do nosso Deus. Creio no poderio do nosso criador em formar um universo cuja complexidade nos seria impossível de compreender. Poderíamos dividir e dividir certo objeto e nunca chegar à sua essência. Cada corpo, objeto e ser desse universo é único, não existe nenhum igual, logo, por qual razão nosso criador haveria de constituir sua criação com pedaços finitos idênticos? Eis o que me referi à quantidades infinitamente pequenas."

É, meu caro, tampouco eu compreendi aquelas questões na época e minha memória me falta com detalhes sobre a conversa. Palavras como átomo e vácuo foram proferidas durante o restante da conversa, mas eu não conseguia acompanhar seus argumentos que misturavam ideias sobre como é formada a natureza, raciocínios matemáticos e sua admiração pelo nosso criador. Mantendo minha bebida em mãos, após terminar de ouvir sua lógica peculiar, lhe perguntei como aquela disputa seria resolvida, se a crítica parecia estar ganhando ouvidos.

"No momento, creio que deixarei este assunto de lado. Há assuntos mais urgentes para tratar, pois em alguns meses iremos inaugurar uma academia científica em Berlim. Além disso, há compromissos com a realeza que ainda tomam muito do meu tempo disponível. Caso meus temores tornem-se realidade, serei obrigado a requisitar uma audiência com os membros da Royal Society para demonstrar, definitivamente, que tanto minha obra matemática fora publicada sem conhecimento do método do Sr. Newton, como ela é desassociada ao trabalho do mesmo."

É triste lembrar que, apesar de sua grande influência na cidade na época, eu ouvi dizerem que seus últimos anos não foram de glória. Com as constantes mortes de seus patronos e ignorado pela realeza da época, este senhor passou seus últimos anos trabalhando doente e seu funeral teve apenas seu secretário presente. Não posso deixar de imaginar que isso tenha alguma relação com sua disputa com o tal Sr. Newton.

Enquanto isso, o trabalho deste senhor está sendo publicado aqui, em Paris, traduzido, nada mais, nada menos, que por uma mulher! Além disso, ouvi em outras conversas que ela acrescentou ideias do próprio Leibniz em seus escritos! Irônico, não? Como eu soube disso? Basta dizer que hoje eu posso até não saber ou conseguir andar na mesma rapidez nesta cidade, mas os perfumes na rua são muito melhores...

Figura 3. Parte 3 - Uma controvérsia matemática (continuação)

Enquanto nas duas primeiras partes utilizamos um narrador como uma consciência externa aos acontecimentos, na terceira parte decidimos utilizar um narrador participante (Herman, 2009). Nessa parte, o narrador é um entregador de cartas que vivia em Hanôver quando jovem e conheceu Leibniz numa entrega de cartas ao filósofo. A escolha desse narrador teve alguns objetivos. A profissão do narrador permite-nos colocar novamente em foco a troca de cartas, uma prática científica muito importante à época de Leibniz, favorecendo, então, que o professor retome as discussões sobre a troca de cartas entre filósofos naturais, e traga, para a discussão, questões relativas a essa 
prática, como o crescimento do serviço postal na Europa no século XVII (Jardim, \& Guerra, 2017).

Além disso, o narrador encontra-se em uma idade avançada, o que nos possibilitou ampliar o alcance cronológico da $\mathrm{NH}$, pois ele narra eventos que ocorreram quando era jovem, além de eventos de dois momentos temporais distintos. A partir desse olhar distanciado no tempo, o narrador apresenta uma opinião sobre os eventos narrados, como sobre o crescimento da cidade de Hanôver, e certa admiração por Leibniz, pelo seu papel nesse crescimento. Ao se aliar à família Brunswick-Lüneburg, Leibniz os auxiliou em tornar Hanôver um eleitorado, elevando seu papel político, pois, assim, o governo conquistava o poder de participar na eleição de Imperadores do Sacro Império Romano Germânico (Riley, 1996). Através dessas opiniões, buscamos trazer uma leitura de um cidadão da época sobre esses eventos, além de inserir alguns comentários cômicos.

O fato de o narrador ser um entregador de cartas nos permitiu colocá-lo como um ouvinte que pode ser comparado ao leitor leigo, quando Leibniz lhe explica sua indignação pelo recebimento de uma carta. Assim, por apresentar questionamentos e muitas dúvidas sobre o que lhe é explicado, buscamos facilitar a leitura dos estudantes com a identificação com o narrador e, ao mesmo tempo, abrir um espaço para o professor destacar que, para produzir conhecimento, que hoje classificamos como "científico", naquele contexto histórico, era importante estar inserido em debates, instituições e em círculos de trocas de informação, como as cartas.

No início da conversa entre o narrador e o filósofo, resumimos eventos capazes de introduzir o leitor à disputa entre Leibniz e Newton. No sexto parágrafo, Leibniz defende a originalidade de seu Cálculo Diferencial, destacando as diferenças entre os fundamentos matemáticos e metafísicos entre seu trabalho e o de Newton. Entendemos que a terceira parte da NH possibilita inspirar discussões e estudos sobre esses fundamentos, abordando a origem do pensamento de Leibniz na ferramenta matemática chamada limite de uma função. Para defender essa ferramenta, ele considera a possibilidade de dividir uma grandeza infinitamente. Essa defesa é pautada na lógica de que o universo não tem limite, é infinito como a concepção de Deus de Leibniz e, logo, a ideia de átomo seria inviável.

Após a defesa de seu método de Cálculo, Leibniz informa ao entregador da possibilidade de ele convocar uma audiência com membros da Royal Society, como fez em 1713 (Jolley, 1994). Como dito acima, optamos pelo narrador contar uma história passada para trazermos à $\mathrm{NH}$ informações sobre os resultados da disputa do Cálculo Diferencial e sobre os últimos anos de Leibniz e, assim, encerrar o recorte selecionado. $\mathrm{O}$ último parágrafo começa com um trecho onde há um "não-dito" sobre a publicação dos trabalhos de Newton, traduzidos por uma mulher. Essa mulher foi Émilie du Châtelet, que em 1749 (ano de sua morte), terminou a tradução para o francês da maior obra de Newton, os Philosophiae naturalis principia mathematica (Iltis, 1973).

A terceira parte conclui a $\mathrm{NH}$ e possibilita inspirar discussões sobre algumas práticas de produção de conhecimento na Europa, no século XVII e XVIII, inclusive 
retomando debates gerados após a leitura das duas outras partes. Como exemplo, o professor pode destacar que durante a vida de Leibniz é possível reconhecer uma grande importância dada pelo filósofo natural às academias científicas, algo ilustrado pelo fato de o mesmo buscar ser aceito na Academia de Ciências de Paris e na Royal Society (McClellan III, 2003; Kreiling, 1968; Hofmann, 2007). O impacto dessas instituições em sua vida pode ser levantado na segunda e terceira partes da narrativa, incluindo discussões sobre a criação da Academia de Ciências da Prússia. Essa academia, a terceira maior da época, foi planejada pelo próprio Leibniz e inspirada nas Academia de Ciências de Paris e na Royal Society, contando com o apoio da realeza prussiana (McClellan III, 2003).

A disputa da primazia do Cálculo Diferencial teve como cenário principal a Royal Society. A terceira parte da $\mathrm{NH}$ possibilita destacar alguns eventos nessa disputa que ilustram a importância de certas práticas desses filósofos naturais. Como exemplo, temos a prática da leitura de cartas realizada em reuniões da Royal Society, a partir da qual os integrantes debatiam o trabalho de outros filósofos naturais. Aqui podem ser destacadas a prática do ler e do escrever, além da ação e formas de organização de filósofos naturais em instituições. Em outras palavras, pode-se destacar o papel que personagens como Fatio de Duillier tiveram nessa disputa, além de destacar que Newton era o presidente da Royal Society à época. Isso lhe conferia prioridade na seleção de cartas para leitura na instituição, além do poder de organizar assembleias para julgar a originalidade do trabalho de Leibniz em comparação ao seu.

Dessa forma, a disputa configura-se como um momento de convergência entre os elementos previamente debatidos, da troca de cartas aos debates realizados na Royal Society, no qual Leibniz teve seu trabalho acusado de plágio por uma assembleia organizada por Newton, que o considerou o criador original do Cálculo. Por fim, a história da formação das instituições científicas também pode ser discutida colocandoas em contraste com outras instituições da época, como a universidade. $\mathrm{O}$ incentivo à produção de conhecimento pelas primeiras, frente à tradição de reprodução do conhecimento dos antigos em universidades pode, também, ser um tema de debate.

\section{Considerações e Implicações}

$\mathrm{Na}$ busca de caminhos capazes de promover um ensino de ciências como um espaço de discussão histórica sobre o processo de construção da ciência, encontramos no ler e escrever de NHs uma estratégia pedagógica com potencial de gerar o debate pretendido. No caso do estudo aqui discutido, centramos nossa atenção na leitura de $\mathrm{NHs}$, considerando que o seu caráter literário estimula a imaginação e provoca reações no nível emocional, como destaca a literatura da área (Klassen, \& Froese-Klassen, 2014a; Klassen, 2006; Graesser, 1981; Graesser et al., 1980). Compreendemos que, através dessas reações, é possível quebrar a resistência de estudantes para com a abordagem histórica no ensino e possibilitar ao professor desenvolver aulas em que estudantes apresentem questionamentos, os colocando, assim, numa posição de protagonistas nas aulas de 


\section{Ciências.}

No estudo aqui apresentado, acrescentamos à literatura da área a perspectiva de trabalhar com NHs como forma de problematizar o processo de construção das ciências. Para cumprir esse objetivo, a NH aqui apresentada, baseada na vertente historiográfica da HCC, foi construída a partir de determinados critérios, com a perspectiva de gerar debates capazes de permitir aos estudantes, com a mediação do professor, identificar e discutir práticas científicas. Assim, na construção da $\mathrm{NH}$, foram utilizadas ferramentas literárias, como: a sequência de eventos, os agentes e o não-falado. Essas ferramentas buscam facilitar o destaque, no texto, de elementos históricos diretamente vinculados às práticas de construção de conhecimento naquele contexto, que hoje são classificadas como científicas, como, por exemplo, a participação na República das Letras, nas academias científicas e a disputa pelo cálculo diferencial. Dessa forma, entendemos que esse estudo agrega às pesquisas já desenvolvidas a construção de uma $\mathrm{NH}$ que trabalhe os elementos próprios desse gênero literário de forma a suscitar o envolvimento do leitor com o texto, e, ao mesmo tempo, agregar discussões específicas sobre o evento histórico trabalhado.

Fora isso, ao trabalharmos a discussão histórica sobre o desenvolvimento da ciência, a partir do enfoque das práticas científicas, possibilitamos, com a própria discussão dos atos de ler e de escrever a NH, problematizar o quanto a leitura e a escrita fazem parte do trabalho na ciência. Em função disso, defendemos que a atividade de leitura da $\mathrm{NH}$ torne-se uma possível estratégia para incentivar a escrita de NHs por parte dos estudantes. Apesar de não ser objetivo desse trabalho discutir o potencial de atividades de escrita, é importante salientar que a partir da leitura da $\mathrm{NH}$, os estudantes poderiam ser convidados a escrever uma $\mathrm{NH}$ ou ainda um outro gênero literário, como contos e poesias, ou a construção de uma reportagem de uma capa de jornal da época (séc. XVII, no caso) ou a invenção de uma carta trocada entre atores do contexto histórico estudado.

Apesar de construirmos a NH com vistas a potencializar debates específicos em sala de aula, ao estimular a imaginação e provocar reações no nível emocional, o caráter literário da mesma pode, ainda, gerar discussões imprevistas em sala de aula, ampliando assim seu potencial pedagógico. Esse poder não previsível dos caminhos possíveis da leitura da NH, em vez de diminuir seu potencial, aumenta sua possibilidade pedagógica, no sentido de permitir aos estudantes trazer às salas de aula questões não planejadas pelo professor. Dessa forma, pesquisas empíricas, como as que no momento estamos desenvolvendo sobre o uso de $\mathrm{NH}$ em aulas de ciências, são importantes para trazer novos elementos que nos permitam construir subsídios para melhor compreendermos as possibilidades do uso de NHs em aulas de ciências. 


\section{Referências}

Almeida, M. J., Silva, H. C., \& Machado, J. L. M. (2001). Condições de produção no funcionamento da leitura na educação em física. Revista Brasileira de Pesquisa em Educação em Ciências, 1(1).

Alvim, M. H., Zanotello, M. (2014). História das ciências e educação científica em uma perspectiva discursiva: contribuições para a formação cidadã e reflexiva. Revista Brasileira de História da Ciência, 7(2), 349-359.

Aduriz-Bravo, A., \& Revel Chion, A. (2016). El pensamiento narrativo en la enseñanza de las ciencias, Inter-Ação, Goiânia, 41(3), 691-704. https://doi.org/10.5216/ia.v41i3.41940

Barthes, R. (1977). Introduction to the structural analysis of narratives, (S. Heath, Trad.). Image Music Text. New York: Hill \& Wang, 79-124.

Brill, G., Falk, H., Yarden, Y. (2004). The learning processes of two high-school biology students when reading primary literature, International Journal of Science Education, 26(4), 497-512. https://doi.org/10.1080/0950069032000119465

Brockliss, L. (2013). Starting-out, getting-on and becoming famous in the eighteenthcentury republic of letters. In M. Feingold (Ed.). History of Science and Medicine Library, 9, 71-100. https://doi.org/10.1163/9789004243910_004

Bruner, J. S. (1986). Actual minds, possible worlds. Harvard University Press Cambridge. Bruner, J. S. (1990). Acts of meaning. Cambridge, Massachusetts, London: Harvard University Press.

Bruner, J. S. (2004a). Making stories: law, literature, life. Nova York: Farrar, Straus and Giroux.

Bruner, J. S. (2004b). Life as a narrative, Social Research, 71(3).

Burke, P. (2011). A república das letras europeia, 1500-2000. Estudos Avançados, 25(72), 277-288.

Burke, P. (2008). O que é história cultural? ( $2^{\mathrm{a}}$ ed). (Sergio Goes de Paula, Trad.), Rio de Janeiro: Jorge Zahar Editora. https://doi.org/10.14195/1645-2259_15_20

Burke, P. (2003). Uma história social do conhecimento: de Gutemberg a Diderot. Rio de Janeiro: Jorge Zahar. https://doi.org/10.1590/S0104-71832004000200014

Carter, L. (2014). The elephant in the room: science education, neoliberalism and resistance. Activist science and technology education, 23-36, Springer, Dordrecht. https:// doi.org/10.1007/978-94-007-4360-1_2

Clough, M. (2011). The story behind the science: bringing science and scientists to life in post-secondary science education. Science \& Education, 20(7), 701-717.

Clough, M. (2009). Humanizing science to improve post-secondary science education. 
International History, Philosophy and Science Teaching Conference, University of Notre Dame, June 24-28.

Daele, W. V. D. (1977). Institutionalisation and definition of positive science in the latter half of the seventeenth century, in. the social production of scientific knowledge. (Mendelsohn, E., Weingart, P., \& Whitley, R., D., Eds.). Reidel Publishing Company.

Daston, L. (2008). On scientific observation, Isis. 99(1), 97-110.

Daston, L. e Galison, P. (2007). Objectivity, Zone Books.

Daston, L. (1991). The ideal and reality of the Republic of Letters in the enlightenment. Science in context, 4(2), 367-386. https://doi.org/10.1017/S0269889700001010

Dodick, J., Argamon, S., Chase, P. (2009). Understanding scientific methodology in the historical and experimental sciences via language analysis, Science \& Education, 18, 985-1004. https://doi.org/10.1007/s11191-008-9146-6

Drummond, J. M. H. F., Nicácio, J. D. S., Skeete Jr., A. W., Silva, M. M. S., Câmara, A. T. A., \& Bezerra, F. V. (2015). Narrativas históricas: gravidade, sistemas de mundo e natureza da ciência, Caderno Brasileiro de Ensino de Física, 32(1), 99-141. https://doi. org/10.5007/2175-7941.2014v32n1p99

Fitas, A. J. S. (1993). Uma controvérsia na história da física. Vértice, 56, 49-61.

Forato, T. C. de M., Pietrocola, M., \& Martins, R. de A. (2012). History and nature of science in high school: building up parameters to guide educational materials and strategies. Science \& Education, 1(5), 657-682.

Ford, M. J. (2015). Educational implications of choosing "practice" to describe science in the Next Generation Science Standards. Science Education, 99(6), 1041-1048.

Froese Klassen, C. (2013). "Stories" created for science teaching: a critical analysis. In P. Heering, S. Klassen, \& D. Metz (Eds.), Enabling Scientific Understanding through Historical Instruments and Experiments in Formal and Non-Formal Learning Environments, 323336. Flensburg: Flensburg University Press. https://doi.org/10.1007/978-94-007-76548_47

Galison, P. (1987). How experiments end. Chicago: University of Chicago Press.

Gavroglu, K. (2007). Uma categoria historiográfica extraordinariamente útil: a prática científica, In Kostas Gavroglu (Ed.). O Passado das Ciências como História, 207-231.

Goodman, D. (1996). The republic ofletters: a cultural history of the French Enlightenment. Cornell University Press.

Graesser, A. C. (1981). Prose comprehension beyond the word. New York: Springer-Verlag. Graesser, A. C., Hauft-Smith, K., Cohen, A. D., \& Pyles, L. D. (1980). Advanced outlines, familiarity, and text genre on retention of prose. Journal of Experimental Education, 48, 281-290. https://doi.org/10.1080/00220973.1980.11011745 
Gurgel, I., \& Watanabe, G. (2017). A elaboração de narrativas em aulas de física: a aprendizagem em ciências como manifestação cultural. (1 ${ }^{\text {a }}$ Ed.). São Paulo: Editora Livraria da Física.

Hadzigeorgiou, Y. (2016). Imaginative science education. Springer.

Hadzigeorgiou, Y., Klassen, S., \& Klassen, C. F. (2011). Encouraging a "romantic understanding" of science: the effect of the Nikola Tesla story, Science \& Education, 21(8), 1111-1138. https://doi.org/10.1007/s11191-011-9417-5

Henke, A., Höttecke, D. (2015). Physics teachers' challenges in using history and philosophy of science in teaching, Science \& Education, 24(4), 349-385. https://doi. org/10.1007/s11191-014-9737-3

Herman, D. (2009). Basic elements of narrative. Wiley-Blackwell.

Herman, D. (2003). How stories make us smarter: narrative theory and cognitive semiotics, Recherches en communication, 19.

Hofmann, (2007). J. Leibniz, parte III, Matemática, Dicionário de Biografias Científicas, v. II, Rio de janeiro: Contraponto Editora, 1607-1613.

Holliday, W. G., Yore, L. D., \& Alvermann, D. E. (1994). The reading-science learningwriting connection: breakthroughs, barriers and promises. Journal of Research in Science Teaching, 31(9), 877-893. https://doi.org/10.1002/tea.3660310905

Iltis, C. (1973). The Leibnizian-Newtonian debates: natural philosophy and social psychology, The British Journal for the History of Science, 6(4), 343-377. https://doi. org/10.1017/S000708740001253X

Jardim, W. T., Guerra, A. (2017). República das Letras, academias e sociedades científicas no século xviii: a garrafa de Leiden e a ciência no ensino. Caderno Brasileiro de Ensino de Física, 34, 774-797. https://doi.org/10.5007/2175-7941.2017v34n3p774

Jolley, N. (1994). Cambridge Companion to Leibniz. Cambridge University Press.

Klassen, S. (2010). The relation of story structure to a model of conceptual change in science learning, Science \& Education, 19(3), 305-31. https://doi.org/10.1007/s11191009-9212-8

Klassen, S. (2009a). The construction and analysis of a science story: a proposed methodology. Science \& Education, 18(3-4), 401-423. https://doi.org/10.1007/s11191008-9141-y

Klassen, S., Froese-Klassen, C. (2014). Science teaching with historically based stories: theoretical and practical perspectives. In M. Matthews (Ed.) International handbook of research in history and philosophy for science and mathematics education, Berlin: Springer, 1503-1529. https://doi.org/10.1007/978-94-007-7654-8_47 
Klassen, S., Froese Klassen, C. (2013). Raising interest in interest: a critical component in learning science through stories and informal learning environments. In P. Heering, S. Klassen, e D. Metz, (Eds.). Flensburg Studies on the History and Philosophy of Science in Science Education, 2, Flensburg: Flensburg University Press (this volume).

Klein, U. (2003). Experiments, models, paper tools: cultures of organic chemistry in the nineteenth century (Writing Science.), Stanford University Press.

Kreiling, F. C. (1968). Leibniz. Scientific American, 218(5), 94-101.

Lamarque, P. (2005). Narrative and invention: the limits of fictionality. narrative in culture; the uses of storytelling in the sciences, philosophy, and literature. In Cristopher Nash (Ed.). Routledge.

Leibniz, G. W. (1976). The Leibniz-Clarke correspondence. In H. G. Alexander (Ed.). Manchester: Manchester University Press.

Leibniz, G. W. (1974). In Col. Os pensadores Leibniz-Newton. São Paulo: Abril Cultural.

Lima, L. G. de, \& Ricardo, E. C. (2015). Física e literatura: uma revisão bibliográfica, Caderno Brasileiro de Ensino de Física, Florianópolis, 32(3), 577-617. https://doi. org/10.5007/2175-7941.2015v32n3p577

Daston, L., Lundbeck, E. (Ed.). (2011). Histories of scientific observation. Chicago: The University of Chicago Press.

Machi, F., \& Leite, C. (2010). A leitura no ensino de física no cenário dos periódicos nacionais. Encontro de Pesquisa em Ensino de Física, XII, 2010, Águas de Lindóia. São Paulo: SBF.

Marras, C. (2011). Leibniz citizen of the Republic of Letters: some remarks on the interconnection between language and politics. Studia Leibnitiana, 43(1), 54-69.

Marcuschi, L. A. (2010). Da fala para a escrita: atividades de retextualização. (10ª Ed.). São Paulo: Cortez.

Martins, A. F. P. (2015). Natureza da ciência no ensino de ciências: uma proposta baseada em "temas" e "questões". Caderno Brasileiro de Ensino de Física, Florianópolis, 32(3), 703-737. https://doi.org/10.5007/2175-7941.2015v32n3p703

Martins, I. (2012). O livro didático de ciências: contextos de exigência, critérios de seleção, práticas de leitura e uso em sala de aula. In Isabel Martins, Guaracira Gouvêa e Rita Vilanova (Eds.). Rio de Janeiro.

McClellan III, J. (2003). Scientific institutions and the organization of science, The Cambridge History of Science, The eighteenth century, 4, Cambridge University Press.

McGuire, J., \& Tuchanska, B. (2013). Da ciência descontextualizada à ciência no contexto social e histórico. Revista Brasileira de História da Ciência, Rio de Janeiro, 6(2), 151-182. 
Metz, D. (2004). Using Historical narratives to guide science experiments, Fifth International Conference for History of Science in Science Education, Keszthely, Hungary, $113-124$.

Metz, D. (2007). We now interrupt the story: mediating student learning using historical stories. Ninth International History, Philosophy and Science Teaching Conference, University of Calgary, Calgary, Canada.

Metz, D., Klassen, S., Mcmillan, B., Clough, M., \& Olson, J. (2007). Building a foundation for the use of historical narratives. Science \& Education, 16, 313-334. https://doi. org/10.1007/s11191-006-9024-Z

Milne, C. (1996a). Is it fair science? School science stories of discovery. In E. Godfrey (Ed.), Proceedings of the Second Australasia and the South Pacific Region GASAT Conference. Auckland, New Zealand: University of Auckland, 86-95.

Milne, C. (1996b). Looking for social justice in school science: reconstructing school science stories. Paper presented at the 21stannual conference of Western Australian Science Educators Association, Perth, Western Australia.

Milne, C (1998). Philosophically correct science stories? examining the implications of heroic science stories for school science, Journal of Research in Science Teaching, 35(2), 175-187. https://doi.org/10.1002/(SICI)1098-2736(199802)35:2<175::AIDTEA7>3.0.CO;2-P

Mody, C. C. M. (2015). Scientific practice and science education; Science Education, 99(6), 1026-1032. https://doi.org/10.1002/sce.21190

Moura, C. B., \& Guerra, A. (2016). História cultural da ciência: um caminho possível para a discussão sobre as práticas científicas no ensino de ciências?. Revista Brasileira de Pesquisa em Educação em Ciências, 16(3), 725-748.

Murmann, M., \& Avraamidou, L. (2014). Narrative as a learning tool in science centers: potentials, possibilities and merits, Journal of Science Communication, 13(2). https://doi. org/10.22323/2.13020202

Newton, I. (1979). Princípios matemáticos. Abril cultural.

Norris, S. P., Guilbert, S. M., Smith, M. L., Hakimelahi, S., \& Phillips, L. M. (2005). A theoretical framework for narrative explanation in science. Published online on May 27th in Wiley InterScience. https://doi.org/10.1002/sce.20063

Pal, C. (2012). Republic of women: rethinking the republic of letters in the seventeenth century, Cambridge University Press.

Pestre D. (1996). Por uma nova historia social e cultural das ciências: novas definições, novos objetos, novas abordagens, Cadernos IG/UNICAMP, 6(1), 3-56. 
Phillips, L. M. (2002). Making new or making do: epistemological, normative, and pragmatic bases of literacy. J. Brockmeir, M. Wang e D. R. Olson (Eds.). Literacy, narrative and culture. Surrey, U.K.: Curzon Press, 283-300.

Phillips, L. M., \& Norris, S. (1999). Interpreting popular reports of science: what happens when the reader's world meets the world on paper?, International Journal of Science Education, 21(3), 317-327. https://doi.org/10.1080/095006999290723

Pimentel, J. (2007). La revolución científica. Historia de Europa, In Miguel Artola Gallego, Martín Almagro Gorbea, Julio A. Pardos Martínez (Aut.). 2, 163-238.

Pimentel, J.(2010). Oquéesla Historia Cultural dela ciencia?ARBOR Ciencia, Pensamiento y Cultura CLXXXVI 743, 417-424. https://doi.org/10.3989/arbor.2010.743n1206

Riley, P. (1996). Leibniz' universal jurisprudence: justice as the charity of the wise. Harvard University Press.

Rivard, L. P., \& Straw, S. B. (2000). The effect of talk and writing on learning science: an exploratory study. Science Education, 84, 566-593. https://doi.org/10.1002/1098237X(200009)84:5<566::AID-SCE2>3.0.CO;2-U

Ross, A. S. (2015). Daum's boys, Manchester University Press.

Schiffer, H., \& Guerra, A. (2012). A utilização de narrativas históricas na construção do conceito de energia: um estudo de caso. In Encontro Nacional de Pesquisadores em Ensino de Ciências, Campinas. VIII ENPEC - I CIEC.

Schiffer, H., \& Guerra, A. (2015). Electricity and vital force: discussing the nature of science through a historical narrative. Science \& Education, 24(4), 409-434. https://doi. org/10.1007/s11191-014-9718-6

Höttecke, D., \& Silva, C. C. (2010). Learning physics with history and philosophy of science. on effective implementation strategies for an old approach in school science teaching in Europe. NMD Garcia, A Pesquisa em Ensino de Física e a Sala de Aula: Articulações Necessárias. São Paulo: SBF.

Stinner, A., McMillan, B. A., Metz, D., Jilek, J. M., \& Klassen, S. (2003). The renewal of case studies in science education. Science \& Education, 12(7), 617-643. https://doi. org/10.1023/A:1025648616350

Taddei, A. M. S. M. (2009). Da narrativa e do narrador em Walter Benjamin. Oralidades, 3(5), 15-30.

Terra, M. R. (2013). Letramento e letramentos: uma perspectiva sócio-cultural dos usos da escrita, D.E.L.T.A., 29(1), 29-58. https://doi.org/10.1590/delta.v29i1.9865

Thurs, D. P. (2015). That the scientific method accurately reflects what scientists actually do. In Ronald L. Numbers and Kostas Kampourakis (Eds.). Newton's apple and other myths about Science, 210-218. 
Van Eijck, M., \& Roth, W-M (2007). Keeping the local local: recalibrating the status of science and traditional ecological knowledge (TEK) in education. Science Education, 91(6), 926-947. https://doi.org/10.1002/sce.20227

Videira, A. A. P. (2007). Historiografa e história da ciência, escritos. Revista do Centro de Pesquisa da Casa de Rui Barbosa. 1(1), 111-158.

Zabrucky, K., Moore, D. (1999). Influence of text genre on adults' monitoring of understanding and recall. Educational Gerontology, 25, 691-710. https://doi. $\operatorname{org} / 10.1080 / 036012799267440$

\section{Hermann Schiffer}

${ }^{0}$ https://orcid.org/0000-0002-1934-9179

CEFET/RJ

Rio de Janeiro, RJ, Brasil

hermannsf@gmail.com

\section{Andreia Guerra}

${ }^{\circledR}$ https://orcid.org/0000-0002-6397-3817

CEFET/RJ

Rio de Janeiro, RJ, Brasil

andreiaguerra@gmail.com

Submetido em 09 de Agosto de 2018 Aceito em 01 de Abril de 2019

Publicado em 04 de Maio de 2019 